endeavours to give a representative picture of the work going on in the Ministry's various laboratories across Canada, more particularly the work directly related to important problems in agriculture and forestry. The extent and variety of this work is shown in a list of 284 research papers published during the year, which is appended to the report. In animal science, investigations were concerned with the basic aspects of nutritional and physiological problems and the protection of livestock and man from animal pests. Experiments in Alberta with spraying and dusting machines, for example, showed that spraying sheep with DDT in the spring was effective against tick, being more rapid than dusting and easier on the animals. Loss of repellency of dimethyl phthalate to mosquitoes was found to be due largely to absorption through the skin, while a rotary-brush spraying device attached to aireraft, which has been developed by the Entomology Division, proved the most effective and economical spraying device so far tested. In plant science, emphasis is placed on researches relating to hazards confronting farmers and foresters from plant diseases and insect pests, and the bulk of the report records the many useful results obtained in such investigations. A further section of the report describes the work in soil science, including microbiology, soil chemistry, taxonomy and antibiotics, while professional services, both organized and informal, which were rendered to different groups within the Depart ment of Agriculture, to other Dominion Departments and to the public, constitute an important feature of the activities of the Department.

\section{Carotid Rete and its Associated Arteries}

A Paper entitled "Studies of the Carotid Rete and its Associated Arteries", by P. M. Daniel, J. D. K. Dawes and Marjorie M. L. Prichard (Phil. Trans. Roy. Soc., B, 237, pp. 173-208 + pls. 12-19; July 1953; $8 s$.$) , records an investigation into the cranial arteries$ in a series of mammals more particularly with respect to the well-known rete mirabile cerebrale, here termed the carotid rete. The animals employed were cat, sheep, ox, goat, pig, dog, rabbit and rat. The rete was found to be well developed in the first five, in a very much reduced form in the dog, but not at all in rabbit or rat. The techniques employed were the use of radio-opaque injection masses from which stereoscopic radiographs were taken, and of injection with neoprene latex. After the setting of the latter, the vessels were dissected in situ or the tissues were completely macerated, leaving only the casts of the blood-vessels. This enabled the position of the main vessels in relation to one another and to the bony tissue, the relation of the vessels to the soft tissue and finally the detailed structure of the rete and its associated vessels, to be readily ascertained. How successful the neoprene latex injections were is clearly shown in the nineteen excellent photographs on the eight plates. The rete is found to be intimately associated with the major arteries supplying the brain, and its presence is associated with a reduction or absence of the internal carotid artery. This is still true of the cat where, in contradistinction to the artiodactyles, the rete is extracranial, lying in a venous lake surrounding the internal maxillary artery immediately below the base of the skull. In the other forms the rete lies intracranially in the cavernous sinus. The rete itself consists of a network of medium-sized arteries about $250 \mu$ in diameter, which interlace and anastomose in a complicated manner. It would appear from its size, its complexity, its relation to the cranial blood supply and its close association with venous blood, that it must serve some functional need; but what this need is or how it is served remain unsolved problems.

\section{The Oriental Earthworm}

THE value of earthworms in increasing fertility of the soil is well known. There are situations, however, in which the good done by earthworms is outweighed by the damage and inconvenience that they cause. In recent years a new species, the Oriental earthworm, Pheretima hupeiensis, has appeared in Connecticut and other eastern states of U.S.A. It has proved to be a much more serious pest than the native species and is more or less immune to treatments used to kill native earthworms. J. C. Schread has described the habits of the new earthworm and experiments on its control in specialized turf areas (Bull. 556 ; April 1952 ; Connecticut Agricultural Experiment Station, New Haven). The worm is apparently very prolific and the production of hundreds of casts following heavy rainfall has seriously damaged golf greens; hundreds of pounds of castings have been left on each heavily infested green every year. Control measures used for native earthworms were not effective in controlling the Oriental earthworm. Parathion applied four times, totalling about a hundred pounds per acre, reduced the population about 97 per cent; some injury was caused by the final application. Chlordane emulsions were more effective than wettable powders. Single treatments using 40 pounds of chlordane per acre had a highly killing effect and prevented reinfestation for long periods of time. Aldrin in the form of either wettable powders or emulsion at the rate of 33 pounds per acre first activated the worms, but provided good control after several weeks. Other chemical reagents also produced good results.

\section{Enzymes of Aspergillus oryzae}

THe sequence of appearance of the enzymes liberated by $A$. oryzae during its growth and some of the properties of these enzymes have been described and discussed in a series of studies by W. G. Crewther and F. G. Lennox (Austral. J. Biol. Sci., 6, 410,428, $447 ; 1953)$. When a strain of the mould Aspergillus oryzae is grown in surface culture on a protein-free sucrose-tartrate medium, enzymes are released into the culture medium in the following order : first, the carbohydrases sucrase and amylase together with phosphatase; second, the proteases and esterases; and third, catalase. Their liberation is accompanied by the appearance of protein nitrogen in the medium and loss in weight of the mycelium. Evidence is presented for the presence of at least two proteases in addition to glycylglycine dipeptidase - one reduces the viscosity of gelatin very rapidly and is believed to act preferentially on the highmolecular-weight fractions of gelatin (the "viscometric protease'), whereas the other degrades the lower molecular components of the gelatin more readily (the 'gravimetric protease'). The $p H$ activity curves for sucrase and amylase also indicate the presence of more than one component. Inactivation of the various enzymes present during incubation at $40^{\circ} \mathrm{C}$. and at different $p \mathrm{H}$ values has been followed. These papers also give a full account of the fractionation and preparation of crystals rich in protease and of the ethanol fractionation of enzymes at low ionic strengths. 